\title{
Impactos da crise da Covid-19 no mercado de trabalho brasileiro
}

Impacts of the COVID-19 crisis on the Brazilian labor market

\author{
LAURO MATTEI $*, * *$ \\ VICENTE LOEBLEIN HEINEN ${ }^{+,++}$.
}

\begin{abstract}
RESUMO: Neste artigo analisam-se possíveis efeitos da crise econômica associada à pandemia da Covid-19 sobre o mercado de trabalho brasileiro. Na primeira parte do trabalho são analisados os dados recentes da PNAD Contínua para estabelecer um breve panorama do mercado de trabalho às vésperas da pandemia, destacando-se as principais tendências sobre a evolução do desemprego e da ocupação nos distintos setores de atividade econômica, bem como sobre os rendimentos do trabalho. Já na segunda parte do estudo são discutidas as medidas adotadas pelo Governo Federal no que se refere ao emprego e à renda e seus prováveis impactos sobre os trabalhadores. Finalmente, a terceira contém as considerações finais do trabalho, momento em que se procura elucidar os principais problemas para a agenda dos trabalhadores diante da nova conjuntura econômica, social e política do país. PALAVRAS-CHAVE: Pandemia; desemprego; informalidade; proteção social.
\end{abstract}

ABSTRACT: This article analyzes the possible effects of the economic crisis associated with the COVID-19 pandemic on the Brazilian labor market. In the first part of the work, recent data from the Continuous PNAD is analyzed to establish a brief overview of the labor market on the eve of the pandemic, highlighting the main trends on the evolution of unemployment and occupation in the different sectors of economic activity, as well as on income from work. In the second part of the study, the measures adopted by the Federal Government with regard to employment and income and their probable impacts on workers are discussed. Finally, the third contains the final considerations of the work, a moment in which it seeks to elucidate the main problems for the workers' agenda in the face of the new economic, social and political situation in the country.

KEYWORDS: Pandemic; unemployment; informality; social protection.

JEL Classification: J23; J30; J38.

\footnotetext{
* Professor Titular do Departamento de Economia e Relações Internacionais e do Programa de Pós-graduação em Administração, ambos da Universidade Federal de Santa Catarina - UFSC, Florianópolis/ SC, Brasil. E-mail: 1.mattei@ufsc.br. Orcid: http://orcid.org/ 0000-0002-1270-8052.

** Coordenador-Geral do NECAT/UFSC e Pesquisador do OPPA/CPDA/UFRRJ.

+ Estudante do curso de Economia da Universidade Federal de Santa Catarina - UFSC, Florianópolis/ SC, Brasil. E-mail: vicenteheinen@gmail.com. Orcid: http://orcid.org/0000-0003-1263-429X.

++ Bolsista do NECAT/UFSC. Submetido 29/Junho/2020: aprovado: 7/Julho/2020.
} 


\section{INTRODUÇÃO}

A partir do processo de conversão da Covid-19 em pandemia mundial, a crise econômica que há algum tempo já deixava sinais de alerta ao sistema econômico global se amplificou. No Brasil, a chegada dessa nova crise é ainda mais grave, uma vez que a economia do país, além de não ter se recuperado da expressiva recessão ocorrida entre os anos de 2015 e 2017, apresentou apenas pequenos sinais de retomada em 2018 e 2019. Com isso, os impactos da crise da Covid-19 na economia nacional em 2020 vêm se somar a um quadro socioeconômico que já se encontrava em franca degradação.

Nesse contexto, é bastante provável que alguns dos efeitos mais dramáticos dessa nova crise econômica serão sentidos fortemente no mercado de trabalho nacional, que já se encontrava em um processo de deterioração desde 2015. Essa nova crise deverá aportar uma discrepância inédita entre a queda no PIB e no nível de emprego, pois, mesmo que as atividades econômicas sejam bastante afetadas nesse processo, o ajuste sobre o volume de trabalhadores empregado tenderá a ser ainda maior, tanto em função dos "cortes de custos" que deverão ser feitos pelas empresas, como pelo caráter das atividades que foram paralisadas. Neste caso, são os segmentos empresariais mais intensivos em mão de obra, como são os casos das micro, pequenos e médias empresas, que estarão mais sujeitos aos impactos negativos da pandemia.

Hoje está claro que os efeitos da Covid-19 no país não serão de curta duração. Não somente o período de aumento do número de pessoas afetadas deverá ser maior do que o previsto inicialmente pelas autoridades sanitárias nacionais, como seus efeitos econômicos deverão se estender pelos próximos anos. Diante de um cenário em que a própria estrutura econômica do país está ameaçada, mais do que nunca se desvela a incapacidade do "mercado" em oferecer soluções adequadas à degradação das condições de vida dos trabalhadores. Em função disso, é fundamental analisar as principais tendências para o mercado de trabalho nacional, bem como a forma que o governo vem atuando diante delas. Esses assuntos se constituem no objetivo central deste texto.

Para tanto, ele está estruturado em outras três seções, além desta breve introdução. Na primeira delas, apresentamos um breve panorama do mercado de trabalho nacional no início de 2020, buscando observar como a nova crise incidirá sobre o cenário vigente. Na segunda seção, abordamos as principais medidas governamentais relativas ao mercado de trabalho, indicando possíveis impactos sobre o emprego e a renda dos trabalhadores. Já a terceira contém as considerações finais do trabalho, procurando elucidar os principais problemas para a agenda dos trabalhadores diante da nova conjuntura. 


\section{A SITUAÇÃO DO MERCADO DE TRABALHO BRASILEIRO ÀS VÉSPERAS DA PANDEMIA}

A segunda década do século XXI apresenta os piores índices de desemprego da história recente do Brasil. Nesse quesito, a crise que atingiu o país ao final de 2014 superou inclusive a acelerada ascensão do desemprego observada na década de 1990. A taxa de desocupação, que flutuava ao redor de 7\% no início de 2014, atingiu seu ápice nos primeiros meses de 2017, quando ultrapassou a marca dos 13\% (Figura 1). Nesse período, o número de desempregados no Brasil mais que dobrou, atingindo 13 milhões de pessoas no auge da crise. Após três anos desse ápice, verifica-se que a situação pouco se alterou. Isso porque, no trimestre que se encerrou em fevereiro de 2020, a taxa de desocupação no país ainda era de 11,6\%, ou seja, apenas 1,6 ponto percentual abaixo da registrada no mesmo trimestre de 2017. Nesse contexto, nem sequer a pequena redução no desemprego observada ao final de 2019 poderia ser considerada uma boa notícia, uma vez que se explica mais pela saída de pessoas do mercado de trabalho do que pelo aumento sustentado de vagas de emprego.

Figura 1: Taxa de desocupação no Brasil

(\%, trimestres móveis entre dezembro de 2013 e fevereiro de 2020)

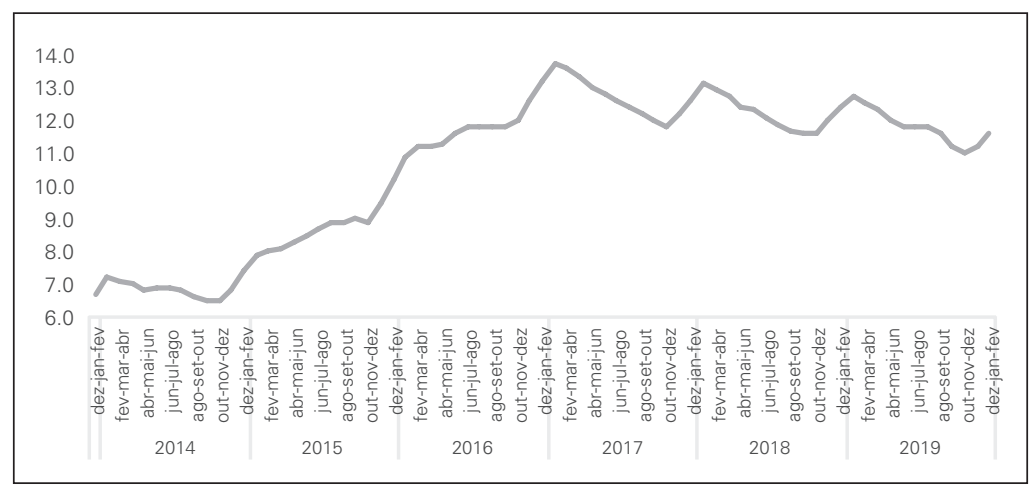

Fonte: PNADC - Divulgação mensal (2020). Elaboração dos autores.

Os dados de fevereiro de 2020 contêm poucas informações sobre os impactos da paralisação das atividades em decorrência da crise deflagrada pela Covid-19. Mesmo os pequenos efeitos negativos já observáveis nesse mês parecem também ter sido dissipados pela redução da procura por trabalho após as primeiras medidas de isolamento social como estratégia de contenção da disseminação da doença. Ainda assim, esses dados ressaltam o fato de que a situação do mercado de trabalho já estava ruim antes mesmo dos impactos da pandemia sobre a economia nacional e sobre o emprego, em particular.

A partir de então tornou-se consenso entre os analistas do mercado de trabalho que a situação deverá se agravar ainda mais e, muito provavelmente, a uma velocidade inédita. No entanto, o grau dessas transformações varia muito entre as diversas 
projeções já publicadas, as quais empregam metodologias distintas de acordo com os interesses que sustentam as pesquisas de cada instituição. Por um lado, o Fundo Monetário Internacional projeta que a taxa de desemprego do Brasil deverá subir para $14,7 \%$ em 2020 , o que pode ser considerada uma estimativa otimista diante da queda esperada de 5,3\% no PIB prevista para o país pela mesma instituição (FMI, 2020). Por outro lado, pesquisa do Serviço Brasileiro de Apoio às Micro e Pequenas Empresas revela que em apenas 15 dias entre os meses de março e abril de 2020 as micro e pequenas empresas já teriam demitido 9,3 milhões de trabalhadores em todo o Brasil (SEBRAE, 2020). Se essas estimativas estiverem corretas, somente o impacto nas micro e pequenas empresas (responsáveis por mais da metade dos empregos do país) já representaria uma elevação da taxa de desocupação para além dos $20 \%$ em abril ${ }^{1}$. Considerando ainda as perdas subsequentes e o conjunto das demissões nas médias e grandes empresas, seria perfeitamente factível esperar uma taxa de desocupação em torno dos $25 \%$ para 2020. Em uma linha intermediária a essas projeções, pesquisadores do Instituto Brasileiro de Economia (IBRE/FGV) estimaram taxas de desemprego entre $17,8 \%$ - supondo que os impactos nos serviços não serão tão intensos quanto na indústria - e 23,8\% - assumindo que o setor de serviços demitirá pelo menos tanto quanto a indústria (Matos et al, 2020).

Nos próximos meses, certamente a taxa de desemprego irá crescer, porém não a tais percentuais. Todavia, deverá crescer o suficiente para dar dimensões mais exatas da deterioração do mercado de trabalho. Como a taxa de desemprego é a razão entre as pessoas que estão procurando emprego e o montante da força de trabalho, medidas de isolamento social adotadas para controlar a pandemia do novo coronavírus poderá reduzir momentaneamente o contingente de pessoas nas ruas em busca de emprego.

Neste sentido, supõe-se que os primeiros sinais da deterioração do mercado de trabalho nacional poderão vir do aumento da população desalentada, ou seja, das pessoas que desejariam trabalhar, mas que por algum motivo não realizam busca efetiva por trabalho. $\mathrm{O}$ volume de desalentados já vinha crescendo continuamente no país desde 2015, atingindo 4,7 milhões de pessoas no início de 2020, o que representava $4,1 \%$ da força de trabalho ampliada (Figura 2). Nos próximos meses, a tendência é de uma ascensão inédita desses números, seja pela adoção da quarentena, seja pela falta de perspectivas de encontrar emprego em um cenário econômico recessivo.

Além disso, devemos considerar também a perspectiva de avanço do desemprego oculto. Nesse caso, a subocupação por insuficiência de horas trabalhadas é uma medida que merece atenção especial, uma vez que indica o grau de insuficiência da renda vigente para atender às necessidades dos trabalhadores. Ao longo dos últimos anos o mercado de trabalho nacional conviveu com elevados índices de subocupação. Com isso, no trimestre encerrado em fevereiro de 2020 sua taxa era de $7 \%$, percentual muito acima dos $5 \%$ da média verificada em 2014. A queda na utilização da capaci-

\footnotetext{
1 Talvez esses fatos contribuam para se entender as razões que levaram o governo a suspender a divulgação do CAGED a partir de fevereiro de 2020.
} 
dade instalada e das horas trabalhadas deverão incidir fortemente sobre esse índice, ao estimular as pessoas a trabalhar mais para retomar seu nível prévio de renda.

Figura 2: Medidas de subutilização da força de trabalho no Brasil

(\%, trimestres móveis entre dezembro de 2013 e fevereiro de 2020)

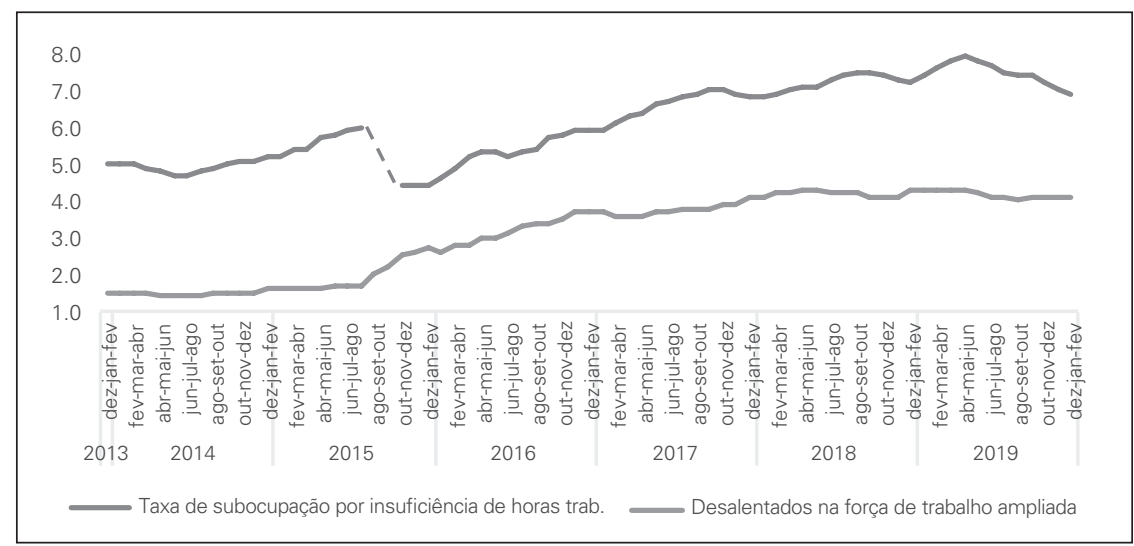

Fonte: PNADC - Divulgação mensal (2020). Elaboração dos autores.

Nota: No terceiro trimestre de 2015 houve uma mudança na metodologia da pesquisa, que afetou

o indicador de subocupação, suprimindo os dados de setembro.

Independentemente dos níveis que o desemprego aberto ou oculto possa assumir, é possível aproximar os cenários anteriormente mencionados sobre a realidade dos trabalhadores fazendo algumas conjecturas sobre os impactos mais imediatos da nova crise nos principais grupos de atividade econômica do país, observando o volume da força de trabalho ocupada em cada um deles.

A partir dos dados da Tabela 1, verificamos que o mercado de trabalho brasileiro apresenta uma tendência de concentração das ocupações no setor de serviços, em detrimento da agropecuária e da indústria em geral. Entre os trimestres encerrados em fevereiro de 2014 e 2020, os grupamentos de atividades que mais perderam ocupações foram os de Agricultura, pecuária, produção florestal, pesca e aquicultura (-1,9\% ao ano); Construção Civil (-1,8\% ao ano); e Indústria Geral (-1,3\% ao ano). Com isso, ao final da série a participação desses setores no agregado foi de $8,9 \%, 13 \%$ e $7,1 \%$, respectivamente.

Em contrapartida, os grupamentos do setor de serviços não só foram os menos afetados pela crise, como também foram responsáveis por quase todos os empregos gerados a partir de 2018. Dentre esses ramos, o maior crescimento anual nas ocupações foi registrado no grupamento de Alojamento e alimentação $(4,6 \%)$, seguido por Outros serviços $(3,6 \%)$ e Transporte, armazenagem e correio (3,2\%). Tomado em seu conjunto, o ramo de Administração pública, defesa e seguridade social, educação, saúde humana e assistência social cresceu $1,7 \%$ ao ano. Todavia, no interior desse grupamento nota-se que todo o saldo positivo se concentrou nos segmentos de educação e atenção à saúde humana, enquanto a administração pública e os serviços sociais apresentaram intensas retrações. 
Tabela 1: Força de trabalho ocupada por grupamento de atividade econômica (mil pessoas e \% nos trimestres encerrados em fevereiro de 2014 a 2020)

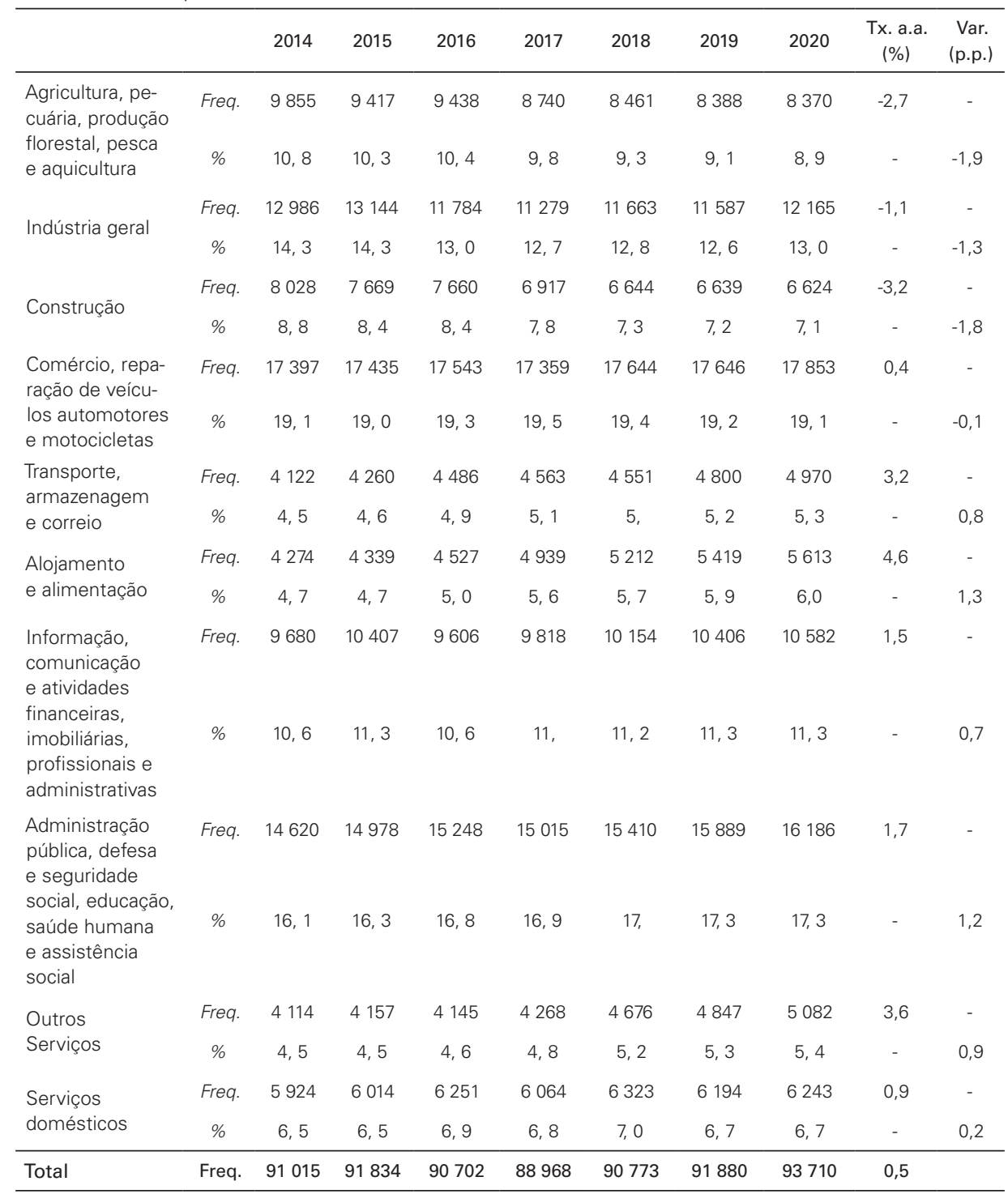

Fonte: PNADC - Divulgação mensal (2020). Elaboração dos autores.

Mesmo assim, o ramo do Comércio (acrescido do segmento de reparação de veículos) ainda é o maior empregador dos trabalhadores brasileiros. Esse setor apresentou pequenas variações em seu estoque de ocupações, inclusive durante a crise, crescendo 0,4\% entre 2014 e 2020. Dessa forma, quando se soma a participação do comércio com os diversos setores do setor de serviços, observa-se que os mesmos detinham $66 \%$ de todos os ocupados em 2014 . Esse percentual atingiu os $71 \%$ no início de 2020. Em grande medida, a concentração dos empregos nesses setores de 
atividade deriva da desindustrialização relativa e da redução da participação do trabalho rural, derivada do avanço da modernização conservadora na agropecuária. Essas distintas configurações do mercado de trabalho do país colaboram para agravar ainda mais os efeitos da crise decorrente da pandemia do novo coronavírus sobre o emprego e a renda, uma vez que as medidas de caráter sanitário para conter o avanço do novo coronavírus irão impactar fortemente esses setores.

A primeira razão para isso é que o comércio deve ser o setor mais afetado pela crise, tanto pela restrição mais imediata de pessoas nas ruas, quanto pela queda na renda das famílias, que guarda relação direta com a demanda do setor. Nesse contexto, os impactos serão menores no comércio atacadista e nas modalidades que podem ser viabilizadas de forma virtual, mas deverão ser maiores no comércio varejista presencial, que é justamente onde se concentra a maior parte dos empregos, e nos setores de pequenos reparos e manutenção.

As mesmas razões devem levar a demissões expressivas no setor de serviços, especialmente no grupamento de Alojamento e alimentação, que já chegou a concentrar $6 \%$ dos ocupados no início de 2020. As medidas de isolamento social fecharam hotéis, bares e restaurantes, e a demanda demorará para voltar a seus patamares anteriores mesmo que governos irresponsáveis autorizem a reabertura desses estabelecimentos sem a correspondente mediação com a curva de controle de expansão da epidemia. Neste período de quarentena, ganharam dimensão as ocupações nas modalidades de tele-entrega, todavia tal alternativa demanda bem menos trabalhadores.

Além do fechamento de praticamente todos os estabelecimentos de serviços pessoais, lazer e cultura, o isolamento social para minimizar o risco de contágio também afetou os trabalhadores que vivem dos famosos "bicos", que compõem parcela importante dos $5,4 \%$ da força de trabalho que estava ocupada no grupamento de Outros serviços. No mesmo sentido, também ficam sob risco de perder suas fontes de renda os trabalhadores domésticos, que representavam $6,7 \%$ dos ocupados em 2020.

O grupamento de Informação, comunicação e atividades financeiras, imobiliárias, profissionais e administrativas concentra serviços variados que já representam $11,3 \%$ dos ocupados no país. Dentre eles estão grande parte dos segmentos que tiveram suas rotinas alteradas pela conjuntura. Nesse caso, as demissões podem ser menores, todavia a tendência é o recurso à redução das jornadas de trabalho (com consequente queda nos salários) e a expedientes como o trabalho em domicílio e os bancos de horas. Essas medidas tendem a fomentar a intensificação do trabalho, especialmente após as mudanças recentes na legislação trabalhista.

Outro grupamento que será fortemente afetado é o dos serviços de Transportes, armazenagem e correios, uma vez que a redução drástica da circulação das pessoas imposta pelo controle da pandemia irá inibir fortemente a demanda, especialmente no caso dos transportes aéreo e rodoviário.

Em termos absolutos, o grupamento de Administração pública, defesa e seguridade social, educação, saúde humana e assistência social deverá ser um dos menos afetado nos próximos meses. Em parte, isso se deve à maior estabilidade dos fun- 
cionários públicos, ainda que possa haver demissões de empregados informais. Com a paralisação das aulas, os empregados no ramo da educação ficam ameaçados, especialmente no caso dos admitidos em caráter temporário (ACTs), mas ainda assim o impacto deve ser menor do que em outras categorias. Já no ramo da saúde e da assistência social a preocupação não é tanto com a perda de empregos mas com as condições de trabalho durante a pandemia, tendo em vista as inúmeras denúncias relativas à falta de equipamentos de proteção individual, por exemplo².

As condições de trabalho também preocupam na construção civil, que foi um dos primeiros setores a ser "liberado da quarentena" em diversos estados do país. Nesse caso, especialmente os trabalhadores de obras de maior porte deverão trabalhar em condições de grande risco, ao mesmo tempo em que o desemprego se espalha entre uma massa de autônomos desamparados por estar na condição de informalidade.

O setor industrial, por ser em geral mais bem organizado comparativamente aos demais, seria um dos ramos em que a adoção de possíveis políticas pró-emprego teoricamente encontrariam menores dificuldades para ser implantadas. Porém, na ausência delas, a tendência é que as indústrias mais atingidas pela queda na demanda reduzam a carga horária de trabalho, suspendam contratos de empregados ou antecipem férias coletivas, enquanto os segmentos menos afetados (a exemplo dos bens de consumo não duráveis essenciais, em geral, e alimentos, em particular) tendem a manter suas atividades. Ainda que as demissões nesse setor inicialmente venham a ocorrer em um ritmo inferior às do comércio e de segmentos dos serviços, a crise também incidirá fortemente sobre a indústria, podendo levar um enorme número de suas empresas à falência, especialmente as micro, pequenas e médias. A consequência será um agravamento do desemprego para muito além do que as autoridades econômicas do Governo Federal estão estimando.

Outro fator que agrava os efeitos da Covid-19 sobre o mercado de trabalho é seu reduzido grau de formalização. Com base nos dados da Tabela 2, notamos que o grau de formalização das ocupações no Brasil era de 55,2\% em 2014 e manteve-se próximo a esse nível até 2016. Desde então, a formalização passou a cair aceleradamente, atingindo seu menor patamar em 2020, quando apenas $52,1 \%$ dos brasileiros encontravam-se em ocupações formais.

Com isso, de 2014 em diante o mercado de trabalho brasileiro já perdeu 2,5 milhões de empregos com carteira de trabalho assinada. O resultado desse processo é que a participação dessa categoria no agregado geral caiu para $37,2 \%$ no trimestre terminado em fevereiro de 2020. Durante esse período, nem sequer o setor público segurou a queda da formalização, uma vez que o número de funcionários públicos estatuários ou militares se manteve estável, representando 8,4\% dos ocupados em 2020.

\footnotetext{
${ }^{2}$ Cf. RBA. Para profissionais da saúde, falta proteção, sobram riscos e angústia. 21 abr. 2020. Disponível em: <www.redebrasilatual.com.br/trabalho/2020/04/pesquisa-profissionais-saude-riscos-angustias>.
} 
Tabela 2: Força de trabalho ocupada por posição na ocupação e categoria

no emprego (mil pessoas e \% nos trimestres encerrados em fevereiro de 2014 a 2020)

\begin{tabular}{|c|c|c|c|c|c|c|c|c|c|c|}
\hline & & 2014 & 2015 & 2016 & 2017 & 2018 & 2019 & 2020 & $\begin{array}{c}\text { Tx. a.a. } \\
\text { (\%) }\end{array}$ & $\begin{array}{l}\text { Var. } \\
\text { (p.p.) }\end{array}$ \\
\hline \multirow{2}{*}{$\begin{array}{l}\text { Empregado com } \\
\text { carteira de trabalho } \\
\text { assinada }\end{array}$} & Freq. & 37416 & 37462 & 35920 & 34717 & 34213 & 34210 & 34827 & $-1,2$ & - \\
\hline & $\%$ & 41,1 & 40,8 & 39,6 & 39,0 & 37,7 & 37,2 & 37,2 & - & $-3,9$ \\
\hline \multirow{2}{*}{$\begin{array}{l}\text { Empregado sem } \\
\text { carteira de trabalho } \\
\text { assinada }\end{array}$} & Freq. & 11711 & 11523 & 10839 & 11279 & 11869 & 12306 & 12847 & 1,6 & - \\
\hline & $\%$ & 12,9 & 12,5 & 12 & 12,7 & 13,1 & 13,4 & 13,7 & - & 0,8 \\
\hline \multirow{2}{*}{$\begin{array}{l}\text { Trabalhador } \\
\text { doméstico }\end{array}$} & Freq. & 5923 & 6008 & 6175 & 6019 & 6273 & 6167 & 6209 & 0,8 & - \\
\hline & $\%$ & 6,5 & 6,5 & 6,8 & 6,8 & 6,9 & 6,7 & 6,6 & - & 0,1 \\
\hline \multirow{2}{*}{$\begin{array}{l}\text { Funcionário público } \\
\text { estatuário ou militar }\end{array}$} & Freq. & 7671 & 7819 & 7783 & 7898 & 7831 & 7905 & 7896 & 0,5 & - \\
\hline & $\%$ & 8,4 & 8,5 & 8,6 & 8,9 & 8,6 & 8,6 & 8,4 & - & 0 \\
\hline \multirow{2}{*}{ Empregador } & Freq. & 3681 & 3962 & 3749 & 4107 & 4334 & 4523 & 4411 & 3,1 & - \\
\hline & $\%$ & 4,0 & 4,3 & 4,1 & 4,6 & 4,8 & 4,9 & 4,7 & - & 0,7 \\
\hline \multirow{2}{*}{ Conta própria } & Freq. & 21077 & 21641 & 23165 & 22051 & 23052 & 23711 & 24477 & 2,5 & - \\
\hline & $\%$ & 23,2 & 23,6 & 25,5 & 24,8 & 25,4 & 25,8 & 26,1 & - & 3 \\
\hline \multirow{2}{*}{$\begin{array}{l}\text { Trabalhador } \\
\text { familiar auxiliar }\end{array}$} & Freq. & 2762 & 2678 & 2244 & 2178 & 2213 & 2145 & 1974 & $-5,4$ & - \\
\hline & $\%$ & 3,0 & 2,9 & 2,5 & 2,4 & 2,4 & 2,3 & 2,1 & - & $-0,9$ \\
\hline $\begin{array}{l}\text { Grau de } \\
\text { formalização }\end{array}$ & $\%$ & 55,2 & 55,6 & 55,7 & 54,7 & 54,7 & 53,1 & 52,7 & 52,1 & $-3,1$ \\
\hline
\end{tabular}

Fonte: PNADC - Divulgação mensal (2020). Elaboração dos autores.

Nota: Grau de formalização dado pela participação dos empregados com carteira de trabalho assinada (inclusive trabalhadores domésticos), funcionários públicos estatuários ou militares e empregadores no total das ocupações.

A redução dessas categorias de emprego obrigou parte da população desempregada a assumir ocupações informais. Dessa forma, os trabalhadores por conta própria passaram de 23,2\% em 2014 para 26,1\% dos ocupados em 2020, significando um crescimento absoluto de $2,5 \%$ ao ano. Ainda que de forma menos intensa, os empregados sem carteira de trabalho assinada também cresceram em termos absolutos ( $1,6 \%$ ao ano) e relativos ( 0,8 pontos percentuais), chegando a abranger $13,7 \%$ das ocupações em 2020.

Essas informações são decisivas para comprovar que a incipiente retomada das vagas observada ao longo de 2018 e de 2019 foi puxada basicamente por ocupações informais. Isso quer dizer que a maioria dos trabalhadores brasileiros se encontra desprotegida pela legislação trabalhista que, mesmo vilipendiada recentemente, ainda representa uma situação melhor com relação às condições de trabalho e à seguridade social. Nesse contexto, nota-se que, por um lado, cerca de $14 \%$ dos empregados informais não possuem nenhuma garantia de estabilidade no emprego e, por outro lado, grande parte dos $26 \%$ de trabalhadores autônomos dependem diretamente da demanda por serviços esporádicos. Em ambos os casos, acumula-se uma massa de trabalhadores "flexíveis", que se encontram desamparados institucionalmente e que permanecem à mercê das flutuações econômicas que, em momento de crise como o atual, lhes impõem perdas imediatas na renda.

Essas tendências provavelmente irão se agravar ainda mais ao longo do ano de 2020, incidindo sobre um cenário que, em termos de renda, já era desfavorável. A partir de 2015, a crise que se instaurou no país promoveu não somente uma 
larga ampliação do desemprego, mas também uma queda dos rendimentos daqueles segmentos de trabalhadores que conseguiram se manter ocupados. Pelas informações da Tabela 3, verifica-se que os salários médios reais no Brasil caíram no biênio 2015-2016, apresentaram uma lenta recuperação entre 2017 e 2018, porém voltaram a se estagnar ao longo de 2019. Com efeito, o rendimento médio real no país no início de 2020 foi de $\mathrm{R} \$ 2.300$, valor muito próximo ao registrado em 2014.

Tabela 3: Rendimento médio real da ocupação principal, habitualmente recebido por mês, por posição na ocupação ( $\$$ \$ nos trimestres encerrados em fevereiro de 2014 a 2020)

\begin{tabular}{|c|c|c|c|c|c|c|c|c|}
\hline & 2014 & 2015 & 2016 & 2017 & 2018 & 2019 & 2020 & $\begin{array}{c}\text { Tx. a.a. } \\
(\%)\end{array}$ \\
\hline $\begin{array}{l}\text { Empregado no setor privado com } \\
\text { carteira de trabalho assinada }\end{array}$ & 2213 & 2213 & 2201 & 2211 & 2261 & 2232 & 2252 & 0,3 \\
\hline $\begin{array}{l}\text { Empregado no setor privado sem } \\
\text { carteira de trabalho assinada }\end{array}$ & 1349 & 1324 & 1335 & 1353 & 1308 & 1427 & 1481 & 1,6 \\
\hline Trabalhador doméstico & 908 & 933 & 926 & 921 & 939 & 939 & 916 & 0,1 \\
\hline $\begin{array}{l}\text { Empregado no setor público como } \\
\text { militar ou servidor estatuário }\end{array}$ & 4025 & 4111 & 3985 & 4121 & 4169 & 4342 & 4281 & 1,0 \\
\hline $\begin{array}{l}\text { Empregado no setor público com } \\
\text { carteira de trabalho assinada }\end{array}$ & 3128 & 3261 & 3277 & 3491 & 3984 & 3932 & 3879 & 3,7 \\
\hline $\begin{array}{l}\text { Empregado no setor público sem } \\
\text { carteira de trabalho assinada }\end{array}$ & 1931 & 1877 & 1941 & 2055 & 1972 & 1972 & 2065 & 1,1 \\
\hline Empregador & 6125 & 6258 & 5688 & 5737 & 5694 & 5873 & 6032 & $-0,3$ \\
\hline Conta própria & 1855 & 1847 & 1744 & 1702 & 1726 & 1757 & 1736 & $-1,1$ \\
\hline Média & 2267 & 2293 & 2213 & 2246 & 2266 & 2306 & 2300 & 0,2 \\
\hline
\end{tabular}

Fonte: PNADC - Divulgação mensal (2020). Elaboração dos autores.

A situação é ainda mais grave tendo em vista a distribuição dos rendimentos pelas categorias de emprego. Os trabalhadores por conta própria foram aqueles que tiveram, ao mesmo tempo, o maior crescimento em volume e o maior decrescimento $(-1,1 \%$ ao ano) em rendimentos reais, recebendo em média $\mathrm{R} \$ 1.736$ no início de 2020. Esse valor só foi superior aos rendimentos dos empregados no setor privado sem carteira de trabalho assinada ( $\mathrm{R} \$ 1.481$ ) e dos trabalhadores domésticos ( $\mathrm{R}$ \$ 916). Já o rendimento dos empregados no setor privado com carteira de trabalho assinada cresceu apenas $0,3 \%$ ao ano no período, auferindo a média de $\mathrm{R} \$ 2.252$ no começo de 2020. Por fim, vale observar que os maiores salários se encontram concentrados entre os empregadores e os trabalhadores formais do setor público, que também apresentaram as maiores taxas de crescimento.

De acordo com microdados da PNAD Contínua Trimestral, 31\% dos ocupados no Brasil recebiam até um salário mínimo ( $\mathrm{R} \$ 998$ ) ao final de 2019. No mesmo período, essa porcentagem chegou a $65 \%$ para as pessoas que recebiam até três salários mínimos (NECAT, 2019). 


\section{AS MEDIDAS DO GOVERNO RELATIVAS AO EMPREGO E À RENDA E SEUS IMPACTOS SOBRE OS TRABALHADORES}

Conforme indicamos em outro trabalho, o Governo Federal não possui um plano de ações devidamente organizado e articulado para amenizar os efeitos da pandemia sobre as atividades econômicas (Mattei; Fronza; Heinen, 2020). No que se refere ao mercado de trabalho, além de desarticuladas, as medidas adotadas podem ser consideradas também prejudiciais, pois invés de buscar preservar os empregos e os salários dos trabalhadores, elas operam exatamente no sentido oposto, ou seja, para estimular o desemprego e rebaixar os salários.

As intenções do governo nesse sentido já ficaram claras pelo menos desde 22 de março deste ano, quando o governo editou a Medida Provisória (MP) n ${ }^{\circ}$ 927, que além de desconfigurar o que restou da CLT, passava a permitir a suspensão dos contratos de trabalho por quatro meses sem pagamento dos salários. Tal MP foi cancelada, em parte, no dia seguinte, em ato no qual o Ministro da Economia confessou que "assinou a MP sem ler", enquanto o Presidente da República tentou se explicar afirmando que "houve um erro na redação".

Guardando as mesmas pretensões, essa medida foi reeditada no dia $1^{\circ}$ de abril de 2020 como MP n ${ }^{\circ}$ 936, mas agora com a pomposa nomeação de Programa Emergencial de Manutenção de Emprego e Renda. A principal alteração promovida pela nova MP em relação à medida anterior foi a permissão da redução da jornada de trabalho com percentuais que podem ser, a princípio, de $25 \%, 50 \%$ ou $70 \%$, com correspondente desconto nos salários, além da autorização para a suspensão do contrato de trabalho (redução de $100 \%$ da jornada e do salário).

No caso da redução das jornadas a medida vale por até 90 dias, sendo que o consequente corte nos salários é proporcionalmente compensado de acordo com o valor do seguro-desemprego ao qual o trabalhador teria direito caso fosse demitido. Particularmente no caso em que esse acordo for firmado em negociação coletiva, o percentual poderá ser diferente dos mencionados acima, todavia o benefício ainda será limitado a essas frações estabelecidas ${ }^{3}$. Caso a opção seja pela suspensão do contrato, a medida é válida por até 60 dias, sendo que o trabalhador deverá receber o valor integral previsto pelo seguro-desemprego. Em ambos os casos, a MP prevê estabilidade no emprego até o dobro do período de redução, ou seja, se a redução/ suspensão perdurar por dois meses, o empregado não poderá ser demitido sem justa causa nos dois meses seguintes. O texto também prevê um valor fixo de $\mathrm{R} \$$ 600,00 aos trabalhadores intermitentes formalizados, de forma semelhante ao auxílio emergencial aos informais.

As regras de funcionamento do programa são distintas em função do fatura-

\footnotetext{
${ }^{3}$ Para as negociações coletivas, as regras são as seguintes: redução inferior a $25 \%$ sem complemento do seguro-desemprego; redução entre $25 \%$ e $50 \%$ com complemento de $25 \%$ do seguro-desemprego; redução entre $50 \%$ e $70 \%$ com complemento de $50 \%$ do seguro-desemprego; redução superior a $70 \%$ com complemento de $70 \%$ do seguro-desemprego.
} 
mento das empresas. Aquelas que adotarem suspensão de contratos ou redução de jornadas e tiverem faturamento de até $\mathrm{R} \$ 4,8$ milhões não precisam fornecer nenhuma compensação ao salário, que será coberto com $100 \%$ do valor do seguro-desemprego, de acordo com o salário-hora contratual. Já para empresas com faturamento acima de $\mathrm{R} \$ 4,8$ milhões, o seguro cobrirá $70 \%$ do valor previsto.

Os acordos poderão ser firmados entre empregadores e empregados, obedecendo aos seguintes critérios: quando a redução de jornada e de salário for de até $25 \%$, o acordo pode ser individual entre as partes, independentemente do nível salarial. Nos demais casos (redução de $50 \%, 70 \%$ ou suspensão de contrato), acordos individuais somente poderão ser celebrados com trabalhadores que recebem menos de $\mathrm{R}$ \$ 3.135,00 ou mais de $\mathrm{R}$ \$ 12.202,12. Trabalhadores com salários entre esses dois valores somente poderão fazer acordos de redução de jornada e de salário mediante convenção coletiva com participação do sindicato da categoria.

A MP 936 também alterou diversas regras da legislação trabalhista em vigor até então, sempre com o objetivo oficial de "preservar empregos". Assumindo que acordos individuais celebrados neste período de calamidade pública prevalecerão sobre os instrumentos legais em vigor (acordado se sobrepondo ao legislado), permitiu-se: o trabalho remoto (teletrabalho, home office); a concessão de férias coletivas com aviso antecedente de apenas 48 horas; a antecipação de férias individuais e de feriados; o regime especial de compensação (banco de horas); e a suspensão de exigências administrativas em segurança e saúde do trabalhador.

A equipe econômica do governo previa que 24,5 milhões trabalhadores com carteira de trabalho assinada firmarão acordos de redução de salário ou suspensão de contratos de trabalho com base na MP 936 até o fim do período de calamidade pública, em 31 de dezembro. Segundo a Secretaria Especial de Previdência e Trabalho do Ministério da Economia, até o dia 23 de abril de 2020 já haviam sido registrados 3,5 milhões de acordos (SEPRT apud O GLOBO, 2020). A maior parte desse montante (58,3\% ou cerca de 2 milhões de registros) é de trabalhadores que tiveram seus contratos suspensos, conforme indicado na Figura 3.

Figura 3: Distribuição dos acordos firmados pela MP 936 por grau de redução da jornada (\%, 1ㅇa 23 de abril de 2020)

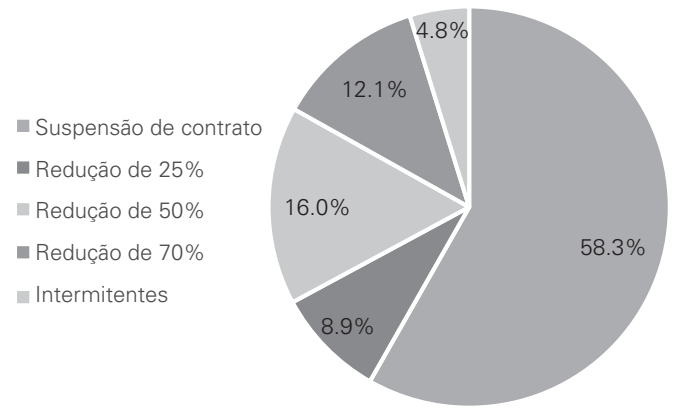

Fonte: Secretaria Especial de Previdência e Trabalho apud O Globo (2020). Elaboração dos autores. 
Uma questão relevante a se perguntar neste momento é: quais serão os impactos dessa medida sobre a renda dos trabalhadores? Levando em consideração as expectativas de alcance do Ministério da Economia e assumindo que a distribuição recente dos acordos entre faixas de jornadas reduzidas e contratos suspensos seja mantida, podemos fazer uma projeção simples, cujos resultados são apresentados na Tabela 4.

No começo de 2020 o rendimento médio dos empregados com carteira de trabalho assinada (inclusive domésticos) era de $\mathrm{R} \$ 2.203,95$. Considerando essa média, a perda salarial seria de $24 \%$ no caso da suspensão do contrato de trabalho; $19,8 \%$ havendo a redução de $70 \%$ da jornada de trabalho; $14,1 \%$ para redução de $50 \%$; e $7,1 \%$ para redução de $25 \%$. Assumindo que os trabalhadores intermitentes efetivamente deixem de trabalhar, estimamos uma queda de $28,2 \%$ em seus rendimentos médios mensais.

Tabela 4: Simulação do impacto da MP 936 nos salários médios e na massa salarial no Brasil (em relação ao trimestre encerrado em fevereiro de 2020)

\begin{tabular}{lcccccc}
\hline & $\begin{array}{c}\text { Suspensão } \\
\text { do contrato }\end{array}$ & $\begin{array}{c}\text { Redução } \\
\text { de } 70 \%\end{array}$ & $\begin{array}{c}\text { Redução } \\
\text { de } 50 \%\end{array}$ & $\begin{array}{c}\text { Redução } \\
\text { de } 25 \%\end{array}$ & $\begin{array}{c}\text { Trab. } \\
\text { Intermitente }\end{array}$ & Total \\
\hline Trabalhadores (mil) & 14284 & 2965 & 3908 & 2181 & 1176 & 24500 \\
Distribuição (\%) & 53,8 & 12,1 & 16,0 & 8,9 & 4,8 & 100 \\
$\begin{array}{l}\text { Salário médio anterior (R\$)* } \\
\text { Salário bruto com }\end{array}$ & $2.203,9$ & $2.203,9$ & $2.203,9$ & $2.203,9$ & $836,0^{* *}$ & - \\
$\begin{array}{l}\text { acordo (R\$) } \\
\text { Perda média (R\$) }\end{array}$ & $1.675,2^{* * *}$ & $1.768,5$ & $1.892,9$ & $2.048,5$ & 600,0 & - \\
$\begin{array}{l}\text { Perda salarial (\%) } \\
528,7\end{array}$ & 435,4 & 311,0 & 155,5 & 236,0 & - \\
\hline $\begin{array}{l}\text { Perda de massa } \\
\text { salarial (R\$ bilhões) }\end{array}$ & 7,6 & 19,8 & 14,1 & 7,1 & 28,2 & - \\
\hline
\end{tabular}

Fonte: PNADC - Divulgação mensal (2020). Elaboração dos autores.

* Rendimentos médios ponderados de empregados no setor privado com carteira e trabalhadores domésticos com carteira.

* Salário médio dos trabalhadores intermitentes formais de 2020 estimados a partir dos valores da Rais de 2018 e da variação do salário mínimo nominal.

** Valor ponderado pela proporção de 50\% dos empregos formais em micro e pequenas empresas E 50\% nas demais, conforme dados do Sebrae (2018).

Supondo um mês em que todos os acordos previstos pelo governo estejam em vigor, podemos esperar uma queda de $R \$ 10,7$ bilhões na massa salarial brasileira somente em função dos acordos autorizados pela MP 936. Em comparação com o montante registrado no trimestre encerrado em fevereiro de 2020 (R \$ 217,6 bi), isso representaria uma queda de aproximadamente $5 \%$ na massa de rendimentos do trabalho do país.

Entre as diversas classes de renda, de fato a perda de rendimentos será proporcionalmente menor quanto menor forem os salários. Todavia, isso não alivia muito a situação dos trabalhadores de baixa renda, uma vez que um trabalhador cujo salário-base ficasse qualquer valor acima do salário mínimo (R\$1.054) já passará a ter algum grau de perda salarial. 
De acordo com os últimos dados oficiais, a maioria dos vínculos formais de trabalho (cerca de 60\%) recebia entre 1 e 3 salários mínimos. Sendo assim, qualquer percentual de redução nas faixas salariais mais baixas já terá um grande impacto em termos agregados. Por exemplo, um trabalhador que recebia dois salários mínimos perderá $13,5 \%$ de sua renda caso tenha a jornada reduzida em $50 \%$, ou até $27 \%$ caso tenha o contrato de trabalho suspenso ${ }^{4}$.

Esses resultados dizem respeito apenas aos trabalhadores com vínculos formais de trabalho. Para o restante da população que depende de seu trabalho, a perspectiva é ainda mais sombria. Até o momento, a única medida aprovada no sentido de aliviar a situação dos cerca de 55 milhões de empregados informais, autônomos e desempregados do Brasil foi o auxílio emergencial de $\mathrm{R} \$ 600,00$ por mês, por até três meses, sancionado em 2 de abril de 2020. Registre-se que se fossem depender do governo, esses trabalhadores iriam receber um valor ainda menor, uma vez que a proposta original desse auxílio feita pelo Ministro da Economia em 18 de março foi de $\mathrm{R} \$ 200,00^{5}$.

O Auxílio Emergencial foi aprovado pelo Congresso Nacional e consolidado na Lei $\mathrm{n}^{\circ} 13.982$, de 28 de março de 2020, que foi regulamentada pelo Decreto $\mathrm{n}^{\circ}$ 10.316, de 7 de abril de 2020, dia em que começaram os primeiros pagamentos. Desde então, acumulam-se inúmeras reclamações de famílias que não conseguiram acessar o benefício ${ }^{6}$. Para se ter uma ligeira noção da dimensão desse problema, basta registrar que técnicos da área social estimam entre 15 e 30 milhões o número de trabalhadores informais fora do CadÚnico do Governo Federal?

Além de todos os problemas causados pelo Governo Federal na implementação do programa, o próprio montante disponibilizado também é insuficiente. Ainda que esse auxílio promova um acréscimo na renda disponível dos desempregados, cabe notar que no trimestre encerrado em fevereiro de 2020 o rendimento médio dos trabalhadores por conta própria era de $\mathrm{R} \$ 1.736$, enquanto o dos empregados sem carteira era de R \$ 1.481. Caso seja concedido, o Auxílio Emergencial cobriria, respectivamente, apenas $35 \%$ e $40 \%$ desses rendimentos, que já eram baixos e, em muitos casos, insuficientes para garantir as condições básicas de vida das famílias. Ainda assim, temos de conviver com diversos preconceitos sociais como aquele

\footnotetext{
${ }^{4}$ Simulações das perdas individuais em função dos acordos da MP 936 podem ser feitas a partir de calculadora elaborada pelo DIEESE, disponível em: <www.dieese.org.br/calculadoramp936/>.

${ }^{5}$ ESTADÃO. Guedes anuncia auxílio mensal de R\$ 200 a trabalhadores informais. 18 mar. 2020. Disponível em: <economia.estadao.com.br/noticias/geral,bolsonaro-diz-que-estuda-medidas-paraajudar-trabalhadores-autonomos-e-socorro-a-aereas,70003238357>.

${ }^{6}$ Cf., por exemplo, BRASIL DE FATO. Após 40 dias de isolamento, trabalhador informal ainda não consegue obter o auxílio. 22 abr. 2020. Disponível em: <www.brasildefato.com.br/2020/04/22/apos-40dias-de-isolamento-trabalhador-informal-ainda-nao-consegue-obter-o-auxilio $>$.

${ }^{7}$ FOLHA DE S.PAULO. A dificuldade de o auxílio emergencial chegar em quem precisa. 29 mar. 2020. Disponível em: <blogdoibre.fgv.br/rss/posts\#_ftnref1>.
} 
explicitado pela atual presidente do Tribunal Superior do Trabalho, para quem "o princípio da dignidade da pessoa humana está [...] absolutamente atendido nessas providências que objetivam manter a inclusão social" ${ }^{8}$.

Em decorrência do que foi apresentado anteriormente, podemos afirmar que não há perspectiva alguma de que as medidas adotadas pelo Governo Federal consigam conter a queda da renda do trabalho no Brasil. Mesmo considerando os efeitos da MP 946 (que autorizou temporariamente o saque do saldo de FGTS até o valor de um salário mínimo por trabalhador), segundo relatório do IBRE/FGV a massa de rendimentos efetivos do trabalho (MRT)

está projetada para cair cerca de $14,4 \%$ em 2020, puxando tanto pela renda média, [...] como pela População Ocupada, que está projetada para cair $6,6 \%$ no ano. Com isso, a MRT estará 3,2\% abaixo do seu menor nível desde o início da série histórica [da PNAD Contínua], em 2012. [...] Mais de R $\$ 30$ bilhões mensais de perda de MRT correspondem a cerca de $5 \%$ do PIB de 2019 (IBRE/FGV, 2020, p. 13).

Essa abrupta queda na renda já está aumentando o nível de endividamento das famílias devendo, inclusive, ampliar a inadimplência das mesmas. De acordo com a Confederação Nacional do Comércio,

o número de famílias com dívidas em cheque pré-datado, cartão de crédito, cheque especial, carnê de loja, empréstimo pessoal, prestação de carro e seguro bateu novo recorde em abril de 2020, alcançando 66,6\% - o maior percentual desde o início da realização da Pesquisa de Endividamento e Inadimplência do Consumidor (Peic), em janeiro de 2010 (CNC, 2020, p. 1).

Entretanto, ao invés de o Governo Federal tentar enfrentar esses problemas com medidas efetivas de manutenção do emprego e da renda, a linha dominante da política econômica parece estar mais preocupada em aproveitar a crise para promover uma nova contrarreforma trabalhista, fatiando a recém-caducada MP n 905 (da "Carteira de trabalho verde e amarela") para atacar simultaneamente as condições de trabalho e os parcos direitos trabalhistas que ainda restam aos trabalhadores ${ }^{9}$.

\footnotetext{
${ }^{8}$ ESTADÃO. "Programa do governo atende princípio da dignidade do trabalhador”, diz presidente do TST. 12 abr. 2020. Disponível em: <economia.estadao.com.br/noticias/geral,reducao-de-salario-naofere-dignidade-do-trabalhador-diz-presidente-do-tst,70003267950>.

${ }^{9}$ Cf. O GLOBO. MP 905: Governo avalia fatiar medida provisória que cria Programa de Emprego Verde Amarelo. 20 abr. 2020. Disponível em: <oglobo.globo.com/economia/mp-905-governo-avalia-fatiarmedida-provisoria-que-cria-programa-de-emprego-verde-amarelo-24383474>.
} 


\section{IMPACTOS DA COVID-19 NO MERCADO DE TRABALHO NO BRASIL SEGUNDO A PNAD CONTÍNUA DE ABRIL DE 2020}

No dia 29 de maio de 2020 o IBGE divulgou os resultados da Pesquisa Nacional por Amostra de Domicílios Contínua (PNAD-C) referentes ao trimestre de fevereiro a abril de 2020. Os principais indicadores considerados revelaram um forte processo de degradação do mercado de trabalho a partir da incorporação de um período de dois meses de influências da pandemia causada pelo novo coronavírus no país. O desemprego - mensurado pela taxa de desocupação - atingiu 12,6\%, representando um montante de 12,8 milhões de pessoas. Registre-se que esse indicador já vinha se mantendo em percentuais bastante elevados no país desde 2016 até recentemente, conforme Tabela 1.

Tabela 1: Taxa de desocupação - Brasil - 2012-2020 (\%)

\begin{tabular}{|l|c|c|c|c|c|c|c|c|c|}
\hline & 2012 & 2013 & 2014 & 2015 & 2016 & 2017 & 2018 & 2019 & 2020 \\
\hline nov-dez-jan & & 7,2 & 6,4 & 6,8 & 9,5 & 12,6 & 12,2 & 12,0 & 11,2 \\
dez-jan-fev & & 7,7 & 6,7 & 7,4 & 10,2 & 13,2 & 12,6 & 12,4 & 11,6 \\
jan-fev-mar & 7,9 & 8,0 & 7,2 & 7,9 & 10,9 & 13,7 & 13,1 & 12,7 & 12,2 \\
fev-mar-abr & 7,7 & 7,8 & 7,1 & 8,0 & 11,2 & 13,6 & 12,9 & 12,5 & 12,6 \\
mar-abr-maio & 7,6 & 7,6 & 7,0 & 8,1 & 11,2 & 13,3 & 12,7 & 12,3 & \\
abr-mai-jun & 7,5 & 7,4 & 6,8 & 8,3 & 11,3 & 13,0 & 12,4 & 12,0 & \\
maio-jun-jul & 7,4 & 7,3 & 6,9 & 8,5 & 11,6 & 12,8 & 12,3 & 11,8 & \\
jun-jul-ago & 7,3 & 7,1 & 6,9 & 8,7 & 11,8 & 12,6 & 12,1 & 11,8 & \\
jul-ago-set & 7,1 & 6,9 & 6,8 & 8,9 & 11,8 & 12,4 & 11,9 & 11,8 & \\
ago-set-out & 6,9 & 6,7 & 6,6 & 8,9 & 11,8 & 12,2 & 11,7 & 11,6 & \\
set-out-nov & 6,8 & 6,5 & 6,5 & 9,0 & 11,8 & 12,0 & 11,6 & 11,2 & \\
out-nov-dez & 6,9 & 6,2 & 6,5 & 8,9 & 12,0 & 11,8 & 11,6 & 11,0 & \\
\hline
\end{tabular}

Fonte: PNADC - Divulgação mensal (2020). Elaboração dos autores.

Por meio do Figura 4 é possível observar que a taxa de desocupação se manteve sempre próxima à casa dos $12 \%$ nos últimos três anos. Com a crise provocada pelo novo coronavírus no trimestre encerrado no mês de abril de 2020, essa taxa cresceu 1,3 ponto percentual (p.p.) com relação ao trimestre anterior (nov-jan), e 0,1 p.p. com relação ao mesmo trimestre de 2019 (fev-abr).

Em termos absolutos, significa dizer que a população desocupada (de 12,8 milhões de pessoas) sofreu um aumento de 898 mil pessoas em relação ao trimestre móvel anterior. Já a população ocupada sofreu uma baixa de 4,9 milhões de pessoas em relação ao trimestre anterior, e de 3,1 milhões de pessoas em relação ao mesmo trimestre de 2019 (feb-abr). Tais quedas, segundo o IBGE, bateram os recordes da série histórica iniciada em 2012. Isso fez com que o nível de ocupação (\% de pessoas ocupadas no conjunto da população em idade de trabalhar) caísse para 51,6\%, correspondendo a uma queda de 3,2 p.p. em relação ao trimestre anterior, cujo 
patamar era de 54,8\%. Com isso, esse indicador se situou no menor patamar da série histórica desde o ano de 2012.

Figura 4: Taxa de desocupação no Brasil

(trimestres móveis encerrados entre abril de 2017 e de 2020, em \%)

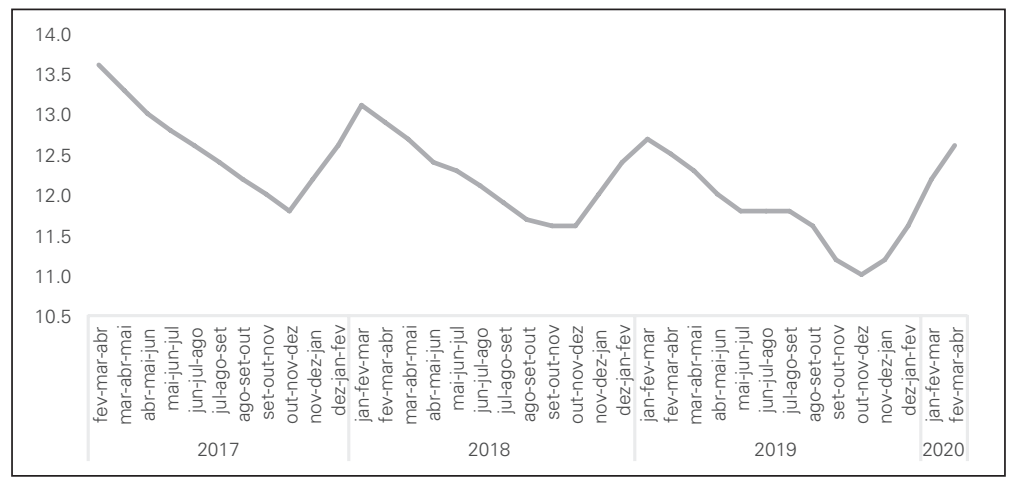

Fonte: PNADC - Divulgação mensal (2020). Elaboração dos autores.

Todavia, a degradação das condições do mercado de trabalho no país não se restringe apenas ao comportamento do indicador de desocupação, conforme mostraremos na sequência ao analisar outros quesitos relativos ao funcionamento do mercado de trabalho, com destaque para dois deles: a população na força de trabalho e a população ocupada.

Primeiramente, cabe notar que a população na força de trabalho (soma das pessoas que estão ocupadas ou não ocupadas e efetivamente procurando trabalho) apresentou a maior queda no trimestre de fevereiro-abril em relação a toda a série histórica da PNAD Contínua iniciada em 2012, implicando uma diminuição de 5,2 milhões de pessoas. Dentre os principais determinantes dessa saída em massa das pessoas da força de trabalho destacam-se os efeitos da pandemia decorrente do novo coronavírus sobre as atividades econômicas, a pouca eficácia da política econômica de apoio ao setor empresarial para manutenção dos empregos, além da falta de perspectivas de se encontrar emprego em uma conjuntura marcada por forte retração das atividades produtivas. Com isso, a taxa de participação na força de trabalho caiu de $61,9 \%$ para $59 \%$ entre os trimestres encerrados em abril de 2019 e de 2020, respectivamente.

A maior parte desses trabalhadores migrou para a força de trabalho potencial (pessoas que desejariam estar trabalhando mas que não procuraram emprego ou que não poderiam assumir alguma vaga de trabalho), que aumentou em 1,9 milhão de pessoas no trimestre. Levando em consideração essa população (que possivelmente também se encontra sem renda do trabalho, de maneira semelhante aos desocupados), pode-se ter uma aproximação mais precisa dos primeiros efeitos da crise da Covid-19 sobre o mercado de trabalho no Brasil. Conforme indicado na Figura 5, a taxa combinada de desocupação e força de trabalho potencial atingiu $20,2 \%$ no trimestre encerrado em abril de 2020, registrando um crescimento de 1,9 p.p. com relação ao trimestre anterior na série dessazonalizada. Esse não é 
apenas o maior crescimento, mas também o maior nível já registrado na série histórica da PNAD Contínua. Concretamente, isso quer dizer que um em cada quatro brasileiros que desejariam estar trabalhando não conseguem fazê-lo atualmente.

Figura 5: Taxa combinada de desocupação e força de trabalho potencial original e dessazonalizada no Brasil (trimestres móveis encerrados entre abril de 2017 e de 2020, em \%).

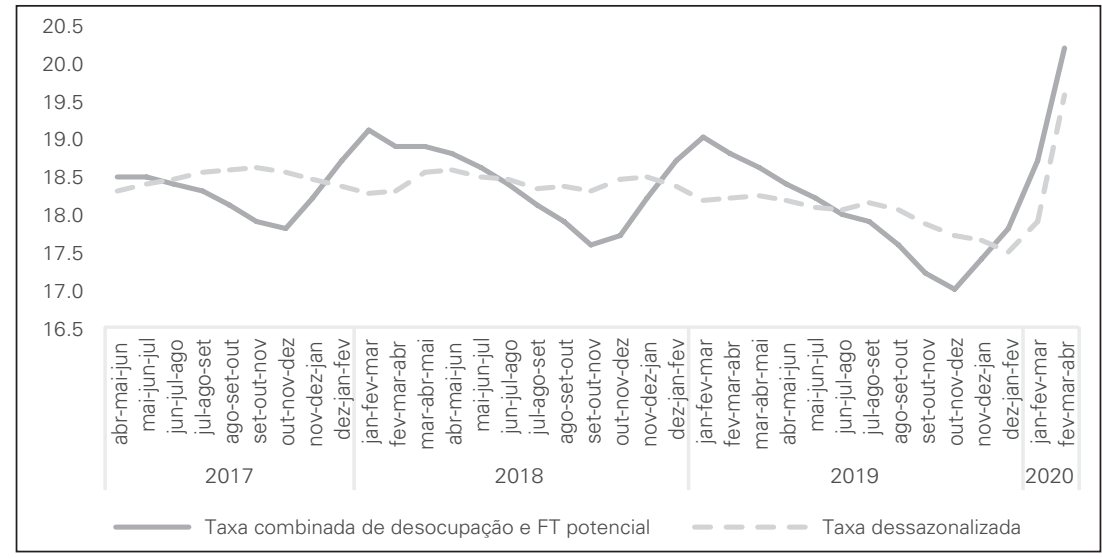

Fonte: PNADC - Divulgação mensal (2020). Elaboração dos autores.

Em grande medida, esse comportamento decorre da própria escassez de vagas de trabalho, impulsionada por fatores como o fechamento de estabelecimentos, as restrições logísticas e a queda generalizada na demanda, tanto interna quanto externa. Com isso, foram fechadas cerca de 5 milhões de ocupações no último trimestre, com relação ao trimestre encerrado em janeiro de 2020. Esse resultado representou uma queda de 4,6\% na população ocupada na série dessazonalizada, conforme Figura 6.

Figura 6: População ocupada no Brasil e taxa de crescimento dessazonalizado (trimestres móveis encerrados entre abril de 2017 e de 2020, em mil pessoas e \%).

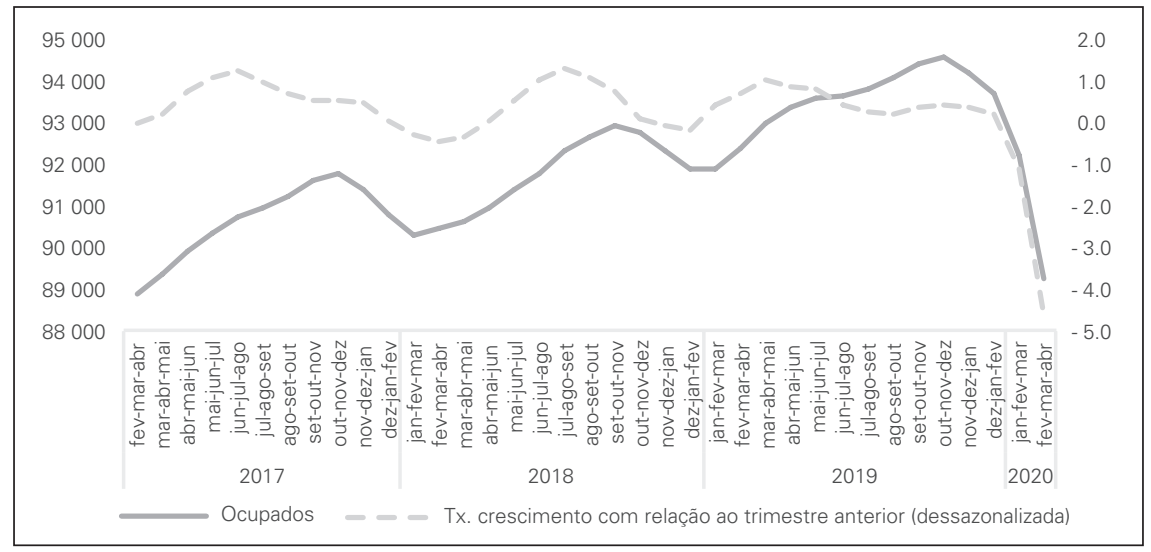

Fonte: PNADC - Divulgação mensal (2020). Elaboração dos autores. 


\section{As principais características das demissões ocorridas no período}

Uma característica importante é que os primeiros a serem demitidos ou a terem seus trabalhos inviabilizados foram os subocupados por insuficiência de horas, que diminuíram em aproximadamente meio milhão no trimestre considerado em relação ao anterior. Esses trabalhadores geralmente se encontram em ocupações mais flexíveis, estando mais sujeitos a desligamentos quando ocorrem retrações na produção.

No que se refere à posição na ocupação, vale destacar que os maiores volumes de demissões se concentraram em três categorias, sendo que cada uma delas perdeu cerca de 1,5 milhão de ocupações no trimestre recentemente divulgado. São elas: empregados no setor privado com carteira de trabalho assinada; empregados no setor privado sem carteira assinada; e trabalhadores por conta própria sem CNPJ. Além disso, o número de empregadores diminuiu 1,2 milhão no período. Neste caso particular, os dados podem estar indicando que os impactos da crise no setor empresarial afetaram mais fortemente os segmentos das micro, pequenas e médias empresas, as quais são responsáveis pela geração da grande maioria das ocupações.

Dentre os setores de atividades, nota-se que o comércio foi um dos mais afetados, uma vez que fechou 1,2 milhão de vagas no trimestre, significando uma queda de $6,8 \%$ em relação ao trimestre anterior. Em seguida, aparecem a construção com $-13,1 \%$, correspondendo a perda de 880 mil vagas; os serviços domésticos com -11,6, significando redução de 730 mil vagas; e as atividades de alojamento e alimentação com $-12,4 \%$, representando diminuição de 700 mil vagas. Apenas o setor de administração pública, defesa, seguridade social, educação, saúde humana e serviços sociais expandiu as vagas em $1,8 \%$.

Com a queda na população ocupada, a massa de rendimento real caiu 3,3\% no trimestre. Já o rendimento médio real de todos os trabalhos aumentou $2 \%$. Em grande medida, esse comportamento da renda pode estar indicando que as pessoas que perderam suas ocupações foram aquelas que integravam as menores faixas de remunerações.

Ainda que os dados analisados captem apenas os primeiros efeitos da atual crise sobre o mercado de trabalho nacional, eles já revelam um processo acelerado de deterioração das condições de emprego e de renda no país. Diante da ineficácia das políticas do Governo Federal no sentido de dar garantias mínimas aos trabalhadores nesse período de pandemia e da forte retração das atividades econômicas, a tendência é que todos os indicadores anteriormente analisados venham a piorar nas próximas divulgações da PNAD Contínua, explicitando, desta forma, a grave situação vivida pelos trabalhadores brasileiros na atualidade.

\section{Grupos de trabalhadores que estão sendo mais afetados durante a pandemia}

Como o mercado de trabalho no país ainda mantém fortes marcas discriminatórias, é bastante provável que os efeitos da pandemia acabem afetando mais fortemente determinados grupos de trabalhadores. Assim, destacam-se na sequência dois grupos sociais que historicamente têm suas trajetórias laborais marcadas 
pela cultura discriminatória que prevalece tanto no mercado de trabalho como na própria sociedade.

Primeiramente destacamos os efeitos gerais da pandemia na vida das mulheres, em função da sua forma de inserção no mercado de trabalho. Por um lado, elas são maioria nos trabalhos domésticos, que ainda permanece com elevado grau de informalidade e, por outro, elas são minoria nos postos de trabalho ligados à produção, como indústrias, construção civil, transportes etc. Ao final de 2019 as mulheres representavam $93 \%$ de todo o emprego doméstico, sendo que a grande maioria $(73 \%)$ nem sequer tinha registro profissional. Quando se cruzam essas informações com a etnia, nota-se que a grande maioria é composta por mulheres negras.

Além disso, as mulheres também são maioria no exercício de atividades ligadas à estética e ao bem-estar. Como esses setores não foram considerados essenciais nas definições de atividades que poderiam funcionar durante a quarentena, certamente tal fato pode ter contribuído para agravar ainda mais as já precárias situações das mulheres no mundo do trabalho.

Informações divulgadas por diversos meios de comunicação revelaram recentemente que as empregadas domésticas foram das primeiras categorias de trabalhadores afastadas de seus postos de trabalho, geralmente sem carteira de trabalho assinada. Com isso, se recolheram em suas casas sem nenhum tipo de remuneração e sem algum direito trabalhista.

Outro grupo social de trabalhadores fortemente afetado é composto pela população negra, tanto homens como mulheres. Além da discriminação de renda já amplamente documentada, são trabalhadores com maior inserção no mercado de trabalho informal. Segundo último informativo de Desigualdades Sociais por Cor e Raça no Brasil elaborado pelo IBGE, a informalidade atingia 48\% dos trabalhadores pretos e pardos, enquanto apenas $35 \%$ dos brancos estavam sob tal condição laboral.

Além disso, a população negra é maioria dentre os brasileiros que trabalham nos comércios de rua nas grandes cidades e metrópoles do país, normalmente atuando como vendedores ambulantes. Com as medidas de isolamento social eles tiveram de ir para suas casas e perderam a fonte diária de renda. São pessoas que normalmente trabalham por conta própria, porém em condições precárias e muito instáveis. Além disso, alguns também fazem parte daquelas atividades que permaneceram funcionando durante a pandemia. Com isso, estavam mais expostos à Covid-19, especialmente aqueles que trabalham em setores e serviços de limpeza ou de entrega de materiais, medicamentos e alimentação.

\section{CONSIDERAÇÕES FINAIS}

Ao contrário da imagem que o Governo Federal, e mesmo algumas instituições internacionais tentam passar, os efeitos econômicos da Covid-19 não terão curta duração. A pandemia deflagrou uma crise mundial que deve reverberar pelos próximos anos. No Brasil, essa crise será utilizada como bode expiatório pelo governo, 
que cinicamente se defenderá de qualquer acusação dizendo que a economia e o mercado de trabalho vinham bem até o início de 2020 .

Conforme ficou evidente ao longo deste texto, a situação já era ruim mesmo antes desta nova crise, de modo que seus impactos no país tendem a ser ainda mais dramáticos. O Brasil iniciou 2020 com uma taxa de desemprego acima de $11 \%$. Diante dos impactos da pandemia sobre a estrutura produtiva e também sobre o nível de consumo, não será nada surpreendente se essa taxa atingir os $20 \%$ ao final do ano, o que conflagraria um cenário em que um em cada cinco brasileiros que necessitam trabalhar não encontram emprego.

Essa situação seria mais facilmente contornável caso a maioria da população estivesse ocupada em empregos formais. No entanto, o grau de formalização das ocupações no Brasil vem caindo continuamente desde 2015, com destaque para a perda dos empregos no ramo industrial. Sem o dinamismo desse setor, uma massa de trabalhadores foi se deslocando para setores de menor produtividade e menores salários, especialmente no comércio e serviços em geral, os quais serviram como válvula de escape à deterioração e queda do emprego formal.

Com isso, cerca da metade dos postos de trabalho do início de 2020 eram ocupações informais. Essa é a parcela dos trabalhadores brasileiros sob risco de ter ficado imediatamente sem renda na nova conjuntura. Nesse sentido, a paralisação das atividades, a desassistência do Estado e a crise econômica que já está em curso em âmbito global tenderão a acirrar ainda mais os problemas do mercado de trabalho nacional não só pelas condições em que os trabalhadores informais se encontram, mas também porque essas ocupações deixarão de ser uma alternativa àqueles que forem sendo demitidos de empregos formais. Esses são, na essência, os problemas de um mercado de trabalho "flexível", condição tanto apregoada pelo ideário econômico neoliberal.

Neste cenário de profundas dificuldades, é imperioso afirmar que as medidas anunciadas pelo Governo Federal - como no caso da MP 936, que autorizou acordos individuais (particularmente entre os trabalhadores com menores remunerações e que recebem até $\mathrm{R} \$ 3.135$ ); a suspensão de contratos (com baixos custos ao empregador); e a redução parcial de salários, levando a uma queda de até 10,7 bilhões na massa salarial - na verdade acabam estimulando e/ou facilitando o desemprego, ao mesmo tempo em que não oferecem nenhum mecanismo efetivo que seja capaz de garantir a estabilidade no emprego por um período mais longo do que alguns meses. Ao lado disso, a própria lei do Auxílio Emergencial, além de ser insuficiente - visto que mal cobre um terço dos rendimentos médios dos trabalhadores informais - não é um mecanismo de renda básica como vendo sendo implementado em outros países.

Em síntese, podemos afirmar que as medidas adotadas até o presente momento não serão capazes de conter a abrupta queda da renda da classe trabalhadora. Ao contrário, tais medidas parecem ir mais no sentido de tornar a degradação do mercado de trabalho nacional permanente do que de garantir um nível de emprego adequado e um patamar de renda suficiente para atender às necessidades básicas da população. Com isso, deverão haver quedas sequenciais na demanda, o que 
contribuirá para que ao longo do próximo período seja retroalimentado o desemprego e elevada a degradação das condições sociais de reprodução da classe trabalhadora. No sentido inverso das medidas que vêm sendo adotadas, os próximos períodos irão mostrar uma vez mais que o problema crucial não é o custo do trabalho, mas a incapacidade da própria dinâmica econômica em gerar novos empregos com qualidade e em quantidades suficientes para atender todos os trabalhadores do país que atualmente se encontram efetivamente fora do mercado de trabalho organizado.

\section{REFERÊNCIAS BIBLIOGRÁFICAS}

CNC. Efeito coronavírus: número de brasileiros endividados bate novo recorde em abril. 13 abr. 2020 . Disponível em: <http://cnc.org.br/editorias/economia/noticias/efeito-coronavirus-numero-de-brasileiros-endividados-bate-novo-recorde>.

FMI. World Economic Outlook, 2020. Disponível em: <bit.ly/2xPyCj7>.

IBRE/FGV. Relatório Macro - Abril de 2020. 2020. Disponível em: <portalibre.fgv.br/data/files/BD/24 155/53/14CA1710199794F68904CBA8/BoletimMacrolbre_2004.pdf>.

MATOS, S. et al. Cenários para a evolução da atividade econômica brasileira em 2020. 2020. Disponível em: <www.joserobertoafonso.com.br/cenarios-atividade-economica-brasileira-2020-matos-et-al/>. Acesso em: 12 abr. 2020.

MATTEI; FRONZA; HEINEN. Trinta dias de anúncios de medidas econômicas para enfrentar os impactos da Covid-19: breve balanço de um desastre anunciado. NECAT, TD 037/2020. Disponível em: <necat.ufsc.br/textos-para-discussao >.

NECAT. Informações do mercado de trabalho: Força de trabalho - PNADC. Disponível em: <necat. ufsc.br/informacoes-do-mercado-de-trabalho/forca-de-trabalho-pnadc/>. Acesso em: 3 mar. 2020.

O GLOBO. MP 936: acordos de redução de salário e suspensão de contrato de trabalho já chegam a 3,5 milhões. 23 abr. 2020. Disponível em: <oglobo.globo.com/economia/mp-936-acordos-de-reducao-de-salario-suspensao-de-contrato-de-trabalho-ja-chegam-35-milhoes-1-24389615>.

PNADC. Divulgação Mensal [IBGE], 2020. Disponível em: <https://www.ibge.gov.br/estatisticas/sociais/populacao/9171-pesquisa-nacional-por-amostra-de-domicilios-continua-mensal. html?=\&t=resultados>. Acesso em: 19 abr. 2020.

SEBRAE. O Impacto da pandemia de coronavírus nos Pequenos Negócios. 2020. Disponível em: $<$ www.sebrae.com.br>.

SEBRAE. Panorama dos pequenos negócios. 2018. Disponível em: <bit.ly/354mszl>. 